\title{
The International Development Research on Cultural Tourism Products of Hainan Overseas Chinese Hometown Culture in the Background of One Belt and One Road
}

\author{
Kundan Zheng ${ }^{1, \text { a }}$ \\ ${ }^{1}$ Haikou College of Economics, Haikou, Hainan, China, 570100 \\ ${ }^{\mathrm{a}}$ email,
}

Keywords: One Belt and One Road, Hainan Overseas Chinese Hometown, International Products

\begin{abstract}
After the urban development strategy "One Belt and One Road", it is favorable by major cities and each city wants to get better development based on this strategy. Hainan hometown as a well-known tourist island, this strategy is put forward from the local advantage and launched a detailed analysis for how to develop an overseas Chinese culture tourism city with Hainan hometown characteristics of overseas Chinese hometown. Based on the current situation, connotation and background of the overseas tourist area in Hainan, this paper puts forward the tourism concept which is more suitable for the development of overseas Chinese in Hainan, realizes the internationalization of tourism and promotes the countermeasure for international products with Hainan hometown characteristics.
\end{abstract}

\section{Introduction}

Hainan as Chinese ancient silk since the ancient times of the important guiding point, in the "one way" strategy under the leadership of the domestic tourism has become a hot city, and with the brand effect, the number of passengers has increased year by year. However, the number of people entering China and the income growth rate of hot money are declining continuously. Among them, the number of inbound tourists in 2010 is 6.633 million, the inbound tourism accounts for 2.56\% and the annual income of inbound tourism is $16.5 \%$ Travel is 66.14 million people, inbound travel accounted for 1.63 person-time, annual income inbound tourism growth rate of $-19.76 \%$ [1]. Summary of the reasons, in addition to the product is not prominent, there are many because of the international high-end tourism market is not enough attraction Therefore, in the "area One Belt and One Road" strategy under the leadership of the Hainan overseas Chinese Qiaoxiang tourism products, international development is of great significance.

\section{Hainan Hometown Tourism under the "One Belt and One Road"}

The Origin of the Strategy of "One Belt and One Road". The earliest "one way all the way" strategy was triggered by the earliest "Silk Road", which was presented by German scholars in 1877, specifically describing the trade routes between China and other international cities. In fact, the Silk Road is not only the trade between China and other countries, but also represents the cultural exchanges between China and other countries. At the same time from the tourism concept, the development of the Silk Road is also a city in the tourist line products. Although the development of the Silk Road for Chinese development has a very important significance, but has been tepid, so with the changes in the times and economic development, in order to better promote the development of the city, "one way" development strategy After the proposed, for the tourism industry set off some upsurge, the government began to tourism routes and tourism product development research more attention, and then enhance the overseas Chinese rural tourism industry development more historical and cultural connotation.

The Role of "One Belt and One Road "Strategy for Hainan Hometown Tourism. First of all, "the way One Belt and One Road" strategy is to meet the needs of the times, is to better promote the development of the city, the economic improvement and proposed for the tourism industry, "one 
way" strategy to promote the development of tourism, but also to Chinese tourism industry has brought more opportunities and challenges. In addition, the tourism industry in Hainan hometown of overseas Chinese, the first Hainan hometown tourism market in accordance with the implementation of this strategy, the use of more preferential policies for the service level and service quality to do a more perfect, and for the introduction of talent, optimization The tourism industry policy system and the development environment. Second in the "one by one" strategy implementation, in order to better improve the Hainan hometown tourism can enter, from the sea, land and air and other aspects of the island to get through the channel, making land and sea. The third use of the strategic design of the historical and cultural resources, make full use of Hainan hometown characteristics, the establishment of Hainan hometown characteristics of tourism products, from the cruise ship, yacht, shopping, ecology and other aspects of improvement, the forces to create the world's deadly tourist The Fourth, the use of the advantages of international market access, and actively carry out cooperation with the international market, to participate in international competition, so that Hainan hometown of overseas Chinese tourism more international development goals.

The Significance of Hainan Overseas Chinese Tourism on the "One Belt and One Road" Strategy. First of all, Hainan hometown as rich tourism resources of the city has a good tourism industry base and more high-quality ecological environment for other countries in the world is very attractive, but also to achieve cultural exchanges with countries, business contacts. In addition, Hainan overseas Chinese as a silk culture of the road culture is more profound, the development of Hainan overseas Chinese tourism products is conducive to building tourism brands, carry forward our culture. At the same time, the development of Hainan hometown has been the main marine industry activity with cruise tourism. It has the function of spreading civilization, promoting friendship and cultural exchange. In the development of Hainan hometown tourism, it makes the exchanges with the neighboring countries more frequently Increased Chinese influence in the international community, to strengthen other countries to participate in "one way along the" initiative. The most important is the representative of Hainan overseas Chinese as a representative of the development of the Boao Forum for Asia, which can be conducive to the role of government diplomacy, more conducive to the implementation of Chinese economic market strategy and the implementation of national peace strategy. Therefore, in order to better implement the "one way One Belt and One Road" strategy and the development of tourism do Hainan overseas Chinese rural culture tourism products in the international development is of great significance.

\section{Tourism Products and the Concept of International Tourism Products}

Tourism Products. The so-called tourism product is simply the local tourism sector, developed according to the characteristics of the region, the use of tourism resources to provide tourists with attractive products and services integrated. First of all, the purpose of tourism is not only to carry out a tourism activities, but tourism activities required by the integration of various services. Tourism products in the classification include tourism products, holiday tourism products, eco-tourism products, special tourism products and tourism safety products. Regardless of any product for consumers who need to spend some time, money, etc. And each product development should have a certain core content and then create a type of products and additional products. Where the core content is what we call the attractions, the staff of the service and the surrounding environment and so on the performance. Additional products are additional services in tourism, such as the proliferation of some souvenirs.

International Tourism Products. With the gradual entry of our country into the international market, many product development and sales will continue to break through the borders, and gradually to the world, tourism is also the same, the nationalization of tourism products is the use of integrated development and marketing tools, making products in the international market Approved process. Its creation and sales are based on international standards, as well as the international needs of the resource allocation, thus constitute the product production, brand marketing and other international. 


\section{The Status Quo of Hainan Overseas Chinese Tourism Products}

With the recent development of Hainan hometowns for the development of tourism products to Hainan hometown of local characteristics of the main development and the introduction of foreign integration, tourism products gradually developed, but compared to the internationalization of tourism products There is a big gap.

First of all, Chinese tourism product development and security mechanisms for the imperfect, there is no specific tourism products in China R \& D departments, while the tourist attractions of the product even if the $\mathrm{R} \& \mathrm{D}$ and innovation, there is no response to the incentive and protection mechanisms. At the same time the current tourism enterprises are small, scattered, weak, poor features, no special innovation and research and development departments. In our country's law there is no special tourism products R \& D results protection, as long as there are more new products developed, there will be a large number of imitators, there are more replicas, making the domestic tourism products in the international market, the lack of competitiveness and innovation.

Followed by the domestic tourist routes clinging to stereotypes too single, the type of tourism products is the lack of new ideas. For overseas tourism in Hainan for many years to the island tourism is characterized by the lack of new ideas, in the leisure travel gradually rising in the era of tourism products and product development efforts are not enough, a lot of software facilities and hardware implementation is not sound enough. At the same time for the Hainan overseas Chinese tourism has been designed for the ocean, ecology, culture, adventure, science and technology and health tourism special tourism has not fully reflected. Although many domestic high-end morning exhibition and the Boao Forum for Asia and other large events held in the country, and by everyone's blitz, but for the market is not competitive enough in the international tourism market share of other tourism products smaller.

In addition to Chinese tourism products, the lack of design research, many tourist attractions travel products thousands of times, do not have high-end, making the homogenization of the product more serious, for the current multi-level, diversified personality market has been unable adapt. Moreover, in Hainan overseas Chinese tourism in the tourism business more, and the same business model, many companies in order to compete for tourists often through the reduction, or even "zero negative fee" model began a malicious competition, the final results often affect The Hainan hometown tourism market reputation.

For Hainan overseas Chinese tourism, tourism products did not fully reflect the hometown of Hainan elements. In many tourists survey and analysis that the Hainan hometown tourism is the sea, the sun and tasting under the Hainan hometown coconut water, and many visitors in the forum said in Hainan hometown only saw two big stones, not the sea of the hometown of overseas Chinese tourists, the Hainan hometown of overseas Chinese characteristics did not play out, which Hainan hometown of overseas sunshine, waves, beaches and the ends of the earth such as a rich cultural connotation and a long history of precipitation cannot make people Feel, is the failure of tourism product development. At the same time Hainan overseas Chinese tourism in Hainan overseas Chinese culture within the lack of tourism cannot achieve the brand effect, for a long history and cultural value of the project is not in the tourism products in the transformation.

The last is the overseas Chinese hometown of Hainan overseas tourism elements of development imbalance. And tourism is nothing more than the "food, shelter, travel, shopping, entertainment, entertainment," the six elements, but the Hainan hometown overseas Chinese tourism to match the elements of the system and the development of the imbalance, the characteristics of the problem is not obvious The degree of generalization is generally low. For the sale of food and tourism goods is basically small, lack of obvious characteristics cannot meet international standards. And tourism classic is not currently strong participation, many tourists can only follow the tour guide everywhere, at night nothing in the room to be, experiential tourism and vacation leisure travel change is not, leading to the international tourism cannot achieve the standard. 


\section{Hainan Overseas Chinese Rural Culture Tourism Products International Development Strategy under the Background of "One Belt and One Road"}

In order to attract more international tourists in the background of " One Belt and One Road ", the international development of cultural tourism products in Hainan hometown of overseas Chinese must take the initiative to interface with the countries along the country, especially some ASEAN countries, The basic product research and development, design, production and sales of international safety and other aspects of the tourism market rules, and fully build a Hainan hometown of overseas Chinese characteristics of marine tourism, ecological and cultural tourism products.

The first in the government to guide the tourism subjective sector to take the lead, the establishment of specialized research and intermediary organizations, in the capital, resource fees and other aspects of tourism products to give full support and help, is designed to have a unique personality Distinctive, easy to market tourism products. In order to better stimulate the tourism enterprises for the development of tourism products, you can develop a more comprehensive incentive policies to encourage, at the same time in the product developed to develop the corresponding tourism products, intellectual property protection laws, safeguard the legitimate rights and interests of enterprises, Tourism products business operation mechanism to enhance the internationalization of Chinese tourism products.

Second, in order to better reflect the personalization of tourism products, first of all can be a combination of differentiated product range of development, such as the development of exhibitions, conferences, training and other aspects of the composite tourism products. Second, according to the different needs of tourists culture, background, ethnic, religious beliefs, similar products in the differentiated design, such as according to different elements of entertainment, health care, ecology, romance, etc. to show the personality of the product. In addition, in the product design, pay attention to the international convergence, so that tourism products have a certain relevance, in the tourist travel can not only get physical and mental relaxation, you can learn knowledge, and can give visitors the pleasure of the spirit.

The third to do a good job in the overseas Chinese hometown of Hainan overseas production of the wrong marketing, Hainan hometown in the natural environment has a rich and colorful landscape, has a profound historical and cultural heritage, so in the production of the product culture, fully tap its culture Connotation, the establishment of Hainan hometown brand uniform style of tourism souvenirs, so that the hometown of overseas Chinese in Hainan overseas hometown of overseas Chinese.

Fourth, do well in Hainan overseas Chinese township brand marketing. You can use the overseas Chinese hometown of Hainan products, as well as policies, tourism facilities and tourism environment, combined with the use of the media for the overseas Chinese hometown of Hainan to establish the overall image, according to the immediate preferences for tourism products pricing, promotional portfolio And so on to promote the development of Hainan hometown overseas Chinese tourism. In addition, you can use the modern network marketing, in the attractions, scenic spots and other COS system using network experience, on the one hand to facilitate visitors to query, on the other hand through the network keyword search design "China Tourism", "China Culture "and so on international positioning, at the same time on the network marketing and domestic and foreign financial enterprises can cooperate, do real-time, secure network payment to facilitate domestic and foreign tourists to use, so that overseas Chinese hometown of Hainan overseas cultural tourism products More international.

\section{Acknowledgements}

1.2016 Hainan Province Philosophy and Social Science Planning Project "Create Hainan overseas Chinese culture tourism model "in the background of "One Belt and One Road" (project number: HNSK (JD16-25)) 
2. 2016 Haikou Economics College School-Level Key Issues "Hainan overseas Chinese cultural tourism international development research under the background of "One Belt and One Road "'" (hjkz16-11).

3, 2016 Hainan Province Philosophy and Social Science Planning Project "Research on digital construction and visual culture communication of Hainan tourism resources" HNSK (ZC) 16-20

\section{References}

[1] Jia Xinzhang, Li Jingyuan. Travel Overview, Vol. 6 (2014) No 53, p.25-26

[2] Peng Sue, Wang Yunhui, Wang Qunyong. Tropical Geography, Vol. 12 (2015) No 27, p.74-76

[3] Qian Xiyuan, Jing Jianfen, Hou XuSiem. Travel Overview, Vol. 30 (2014) No 19, p.144-145

[4] Wang Kuailiang. Journal of Hainan Overseas Chinese University of Radio \& TV, Vol. 29 (2008) No 27, p.21-23

[5] Zhang Gongxu, Sun Jing. Decision Advice, Vol. 8 (2013) No 27, p.57-60 